$10 \mathrm{IKC}-133$

\title{
NEW DATA ON THE STRUCTURE OF THE CUBIC HABIT DIAMONDS FROM THE M.V. LOMONOSOV DIAMONDS DEPOSIT (ARCHANGELSK DIAMONDIFEROUS PROVINCE, RUSSIA)
}

\author{
Kriulina* G.Y., Kyazimov V.O., Vasiliev E.A., Matveeva O.P. \\ M.V. Lomonosov Moscow State University, Moscow, Russia; G.V. Plekhanov Saint-Petersburg GGI (Technical Univeristy), Saint- \\ Petersburg, Russia galinadaimond@gmail.com
}

M.V. Lomonosov diamond deposit is located in the Zolotisky field, Archangelsk Diamondiferous Province (ADP), European part of Russia (Fig. 1). The deposit is presented by 6 kimberlite pipes with II-type kimberlites (Garanin, 2001). Currently, mining is carried out in Archangelskaya pipe. Wide-spread occurrence of cubic habit diamonds is typomorphic feature of the deposit (Kudryavtseva et al., 2005).

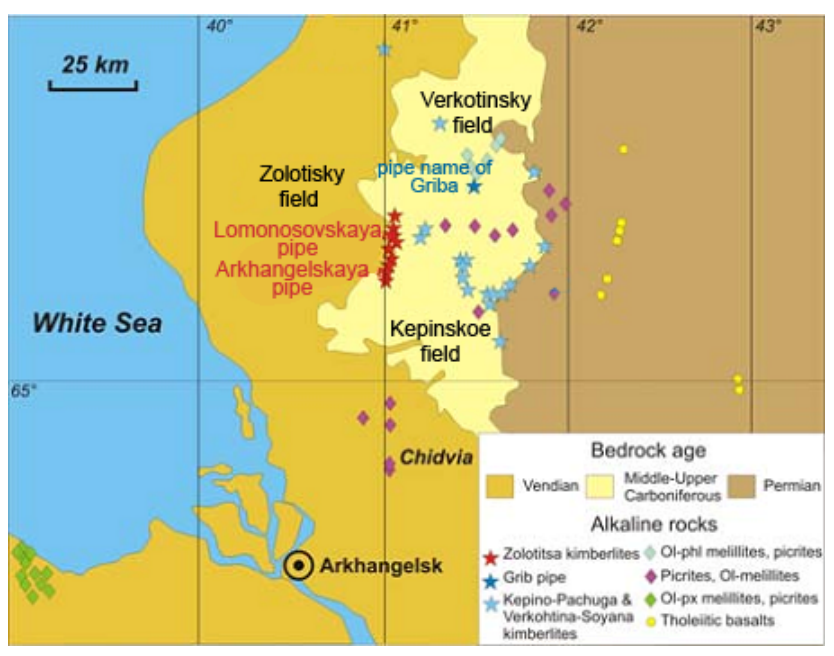

Fig.1. Simplified geological map of the Arkhangelsk alkaline igneous province

Diamonds from Archangelskaya pipe were studied and compared with similar diamonds from Karpinskogo-1 pipe, which were studied antecedently. Cubic diamonds are varying in the M.V. Lomonosov deposit kimberlites.
Transparent visually homogeneous yellow, orange-brown (with different intensity of color) cubic habit diamonds with straight or saddle-shaped faces, and combinative diamonds with cube and tetrahexahedron faces were selected from all crystals variety for investigation. These diamonds present II-variation according well-known in Russia Y.L. Orlov's classification (1984). Diamonds weight was 0.04-0.4 cts. Primary diamonds grinded parallel to the (100) up to a half of the crystal volume for disclosure their internal structure.

Investigation technique. Diamonds' defectimpurity composition was studied at crystals profile (central part and rim) by infra-red spectrometry (IRS) in SPGGI (analyst Dr. E.A. Vasiliev). Spectrum registration was realized using Fourier-transform spectrophotometer VERTEX-70 Bruker with Hyperion-1000 microscope. Spectrums were registered with resolution 4 and $1 \mathrm{~cm}^{-1}$. Defect concentrations were calculated according published methodology (Boyd et. al., 1994; 1995). A (1282 cm $\mathrm{cm}^{-1}$, B $\left(1175 \mathrm{~cm}^{-1}\right), \mathrm{C}\left(1135 \mathrm{~cm}^{-1}\right) \mathrm{N}$-defect concentrations were determined. Abundance of platelets (P) and hydrogen centers $(\mathrm{H})$ in diamonds were estimated 1370-1362 $\mathrm{cm}^{-1}$ and $3107 \mathrm{~cm}^{-1}$ correspondingly according absorption coefficient.

Photoluminescence study was carried out using spectrofluorometer Fluorolog FL3 Horiba at room temperature and in liquid nitrogen $(77 \mathrm{~K})$ (analyst Dr. O. 


\section{$10^{\text {th }}$ International Kimberlite Conference, Bangalore - 2012}

Matveeva, SPGGI). Spectral range was 200-1000 nm. The luminescence spectrums registration and decay kinetics was carried out with excitation of xenon lamp in the wavelength range 250-600 $\mathrm{nm}$ with an excitation bandwidth $5 \mathrm{~nm}$.

The color cathode luminescence (CCL) emission images of diamonds were obtained using a scanning electron microscope (SEM) Stereoscan MK-IIA alsc equipped photorecorder for receiving cathodoluminescen 1 images in real colors (analyst Dr. P.V. Ivannikov, MSU).

Measurement of carbon isotope composition was performed on the analytical complex, which includes elemental analyzer Flash EA 1112, coupled with a mass spectrometer Delta V Advantage (analyst Dr. V.L. Andreicheva, Komi Geological Institute of RAN). The values were given in ppm $\delta^{13} \mathrm{C}$ relative to the PDB standard. The measurement error is $\pm 0.2 \%$ o $(1 \sigma)$.

Results and discussion. According internal structure and defect-impurity composition visually homogeneous yellow-colored crystals of cubic habit from M.V. Lomonosov deposit are divided into three morphogenetic groups (Table 1): 1 - cubes with an uniform or zonal structure, defects only in the form of single nitrogen atoms (C-center) and plastic deformation bands; 2 - "classic cubes" with an uniform internal structure, or a rectilinear zoning on the cube with the presence of nitrogen defects in $\mathrm{A}$ - and $\mathrm{C}$-form, and additional peaks in the range 1374-1354 and 3310-2945 $\mathrm{cm}^{-1} ; 3$ - "zoned cubes" with the central zone formed by the tangential or the normal growth mechanism and characterized by different nitrogen distribution in C-, A-, B-forms. The absorption spectrums of some diamonds from these morphogenetic groups are shown in Fig. 2.

The $\mathbf{1}^{\text {st }}$ group of diamonds is presented by color cubes with smooth face surfaces or with a cubetetrahexahedron combination of the faces. Coloration is from yellow to orange-brown. In these crystals, a high content of nitrogen is in the C-center (275 at.ppm), A-and
B-centers are absent. Blue luminescence is weak. The spectrum contains a system of emission bands N3 and the bands $350,396,570 \mathrm{~nm}$.

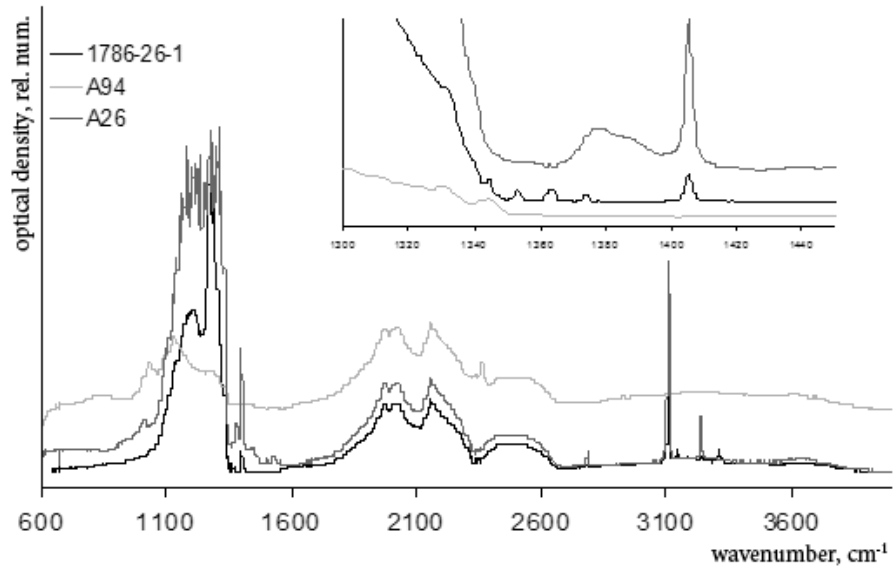

Fig. 2. Absorbance spectrums of diamonds with C-defects (diamond № A94, resolution $4 \mathrm{~cm}^{-1}$ ), with A- and C-defects (1786-26-1, resolution $1 \mathrm{~cm}^{-1}$ ), and A-, B-, P-defects (diamond № A26, resolution $1 \mathrm{~cm}^{-1}$ ). The inset shows the enlarged range 1300$1440 \mathrm{~cm}^{-1}$

$1^{\text {st }}$ group of diamonds are characterized by parallel bands oriented parallel to (111) and a red glow in the CCL, due to the presence of plastic deformation traces in the recorded EPR spectra (Fig. 2) according with EPR - centers (Makeyev et al, 2011). The crystals have homogeneous fibrous structure or can be presented by very thick coat and primary cubic or octahedral shape. The carbon isotopic composition is $-4,9 \%$ - the heaviest among the studied cubic habit diamonds.

The $\mathbf{2}^{\text {nd }}$ group of diamonds is presented by transparent different color intensity yellow cubic habit diamonds with saddle-shaped faces (with large deep negative tetragonal stepped pyramid), rarely with additional tetrahexahedron surfaces. The crystals have a blue glow in the CCL rays, and define by fibrillar homogeneous internal structure. Fluorescence glow is bright blue due to the presence of N3-defect (415 nm), and weak expression of H3-defect in the 503-570 nm. 


\section{$10^{\text {th }}$ International Kimberlite Conference, Bangalore - 2012}

The $2^{\text {nd }}$ group diamonds are characterized by the average content of nitrogen defects in A- and C- centers $\left(300<\mathrm{N}_{\text {tot }}<1000\right.$ at.ppm), while nitrogen in the A-center significantly dominates, and there are no B- or P-centers. Not enough investigated bands at frequencies 1353, 1363, $1374 \mathrm{~cm}^{-1}$ (band $1363 \mathrm{~cm}^{-1}$ is sometimes found separately) are manifested in the absorption spectrums (Fig. 2). A set of narrow bands at frequencies 3310, 3188, 3144, $2945 \mathrm{~cm}^{-1}$ (Fig. 3) are logged in the spectrums of some yellow cubic crystals. Probably, these bands belong to different structural modification of the $\mathrm{CH}$-link.

Diamonds of the $2^{\text {nd }}$ group have the heaviest isotopic composition $\left(\delta^{13} \mathrm{C}\right.$ center/rim $=-4,1 /-4,4 \%$ ).

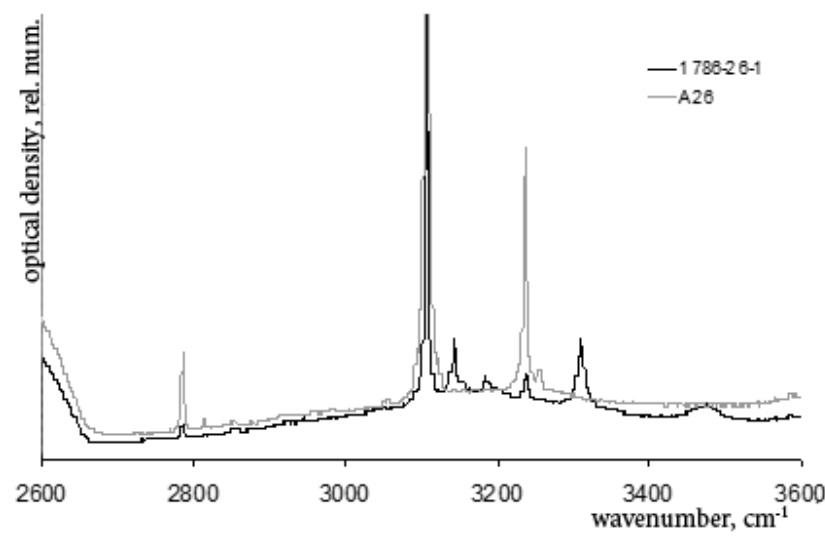

Fig. 3. Diamond (№ 1786-26-1) absorbance spectrums with a set of narrow bands in the range of $\mathrm{CH}$-group fluctuations and normal absorption spectrum in this range for diamond (№ A26), resolution $1 \mathrm{~cm}^{-1}$.

The $\mathbf{3}^{\text {rd }}$ group of diamonds are characterized probably by the longest mantle evolution. These cubic crystals are yellow, yellow-brown transparent or translucent, the presence of the nucleus is determined only by CCL, expressed in different intensities of blue (from blue to dark blue) emission. Such diamonds have a complex zonal structure. The core of the octahedral or cubic form (contains nitrogen defects in the A- and B-centers) is in the central zone. The rim zone of the crystals is formed with normal or mixed growth mechanism. According to the IRS all the crystals of the $3^{\text {rd }}$ group have high N-content: 900 $<\mathrm{N}_{\text {tot }}<1750$ at.ppm.

There is a regularity: crystals with cubic embryo in the rim zone contain only the defect in A-center, diamonds from multiple straight-linear zonation by the cube have defects in the A-and B- centers in the coat and core, and diamonds with the octahedral core have defects in the of A-, B-, C- centers form in the fibrous coat. The band 1362-1378 $\mathrm{cm}^{-1}$ is determined for $30 \%$ of the $3^{\text {rd }}$ group diamonds. Zones with normal, tangential and mixed growth mechanism are repeated 2-3 times in some crystals.

These crystals are composed by zones with different geometry and have a seed crystal (a very small octahedral core) as it can be seen in CCL images. Luminescence is very bright and varied in color. The structure complexity is reflected in the photoluminescence spectrums, containing in addition to the main $(\mathrm{N} 3, \mathrm{~S} 3, \mathrm{H} 3)$ bands with maximums at 313, 347, 396, 411, 482, 500, 649, $671 \mathrm{~nm}$. The lightest part of the carbon $\left(\delta^{13} \mathrm{C}=-9,8 \%\right.$ o $)$ observed in the cubes with the normal growth mechanism and straight-linear zoning over the cube in the CCL rays. In the zoned crystals, marked a slight worsening pattern of carbon isotope composition in the direction of the edge $\left(\delta^{13} \mathrm{~S}\right.$ center / edge $=-7,1 /-5,4 \%$ and $-9,8 /-8,4 \%$ o $)$. A pattern of carbon isotopic composition slight worsening in the direction of the edge $\left(\delta^{13} \mathrm{C}\right.$ center/edge -7,1/-5,4\%o and $9,8 /-8,4 \%$ o) was recorded in zonal crystals.

Conclusion. The formation of outwardly identical cubic diamond in the Archangelskaya pipe indicates highly supersaturated conditions during the last stage of diamond crystallization, and single deep mantle source with a fixed carbon isotopic composition $\left(-4,9<\delta^{13} \mathrm{C}<-9,8 \%\right.$ ) on the basis of the carbon isotopic composition data (Galimov, 1994). 


\section{$10^{\text {th }}$ International Kimberlite Conference, Bangalore - 2012}

These values are typical for the cubes from M.V. Lomonosov and others World's diamond deposits (Galimov, 1984).

Table 1

Structure and defect-accessories composition of cubic habit diamonds from the Archangelskaya pipe

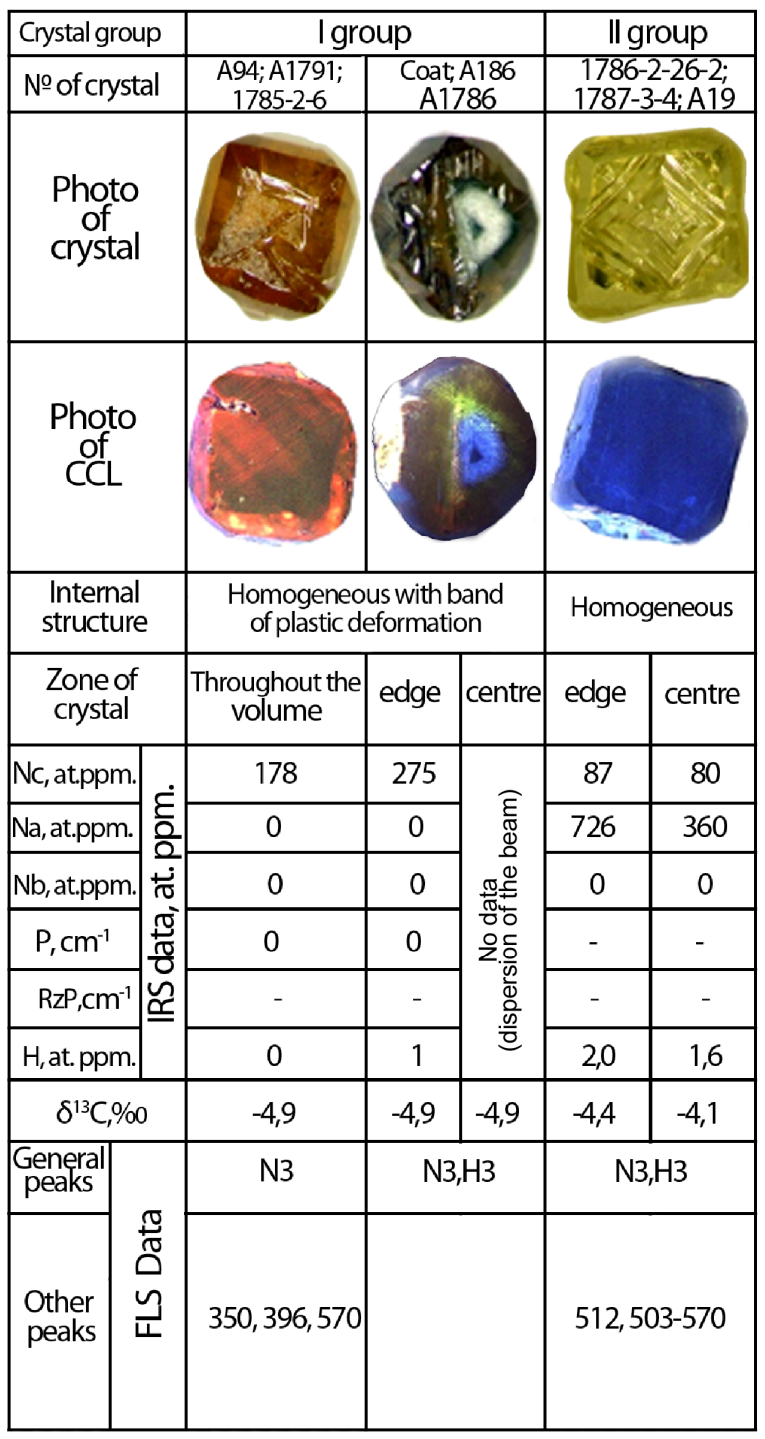

A wide variety of the internal structure forms suggest a complex multistage history of diamonds crystallization in repeatedly changing the environment chemistry. The presence of abrupt change in the growth mechanisms, changes in the defects concentrations and their transformation (defects B- and P- centers) show a discretisation of the diamond genesis, the possibility of long breaks and short-term annealing of these crystals (Taylor et. al., 1995).

Ending table 1 Structure and defect-accessories composition of cubic habit diamonds from the Archangelskaya pipe

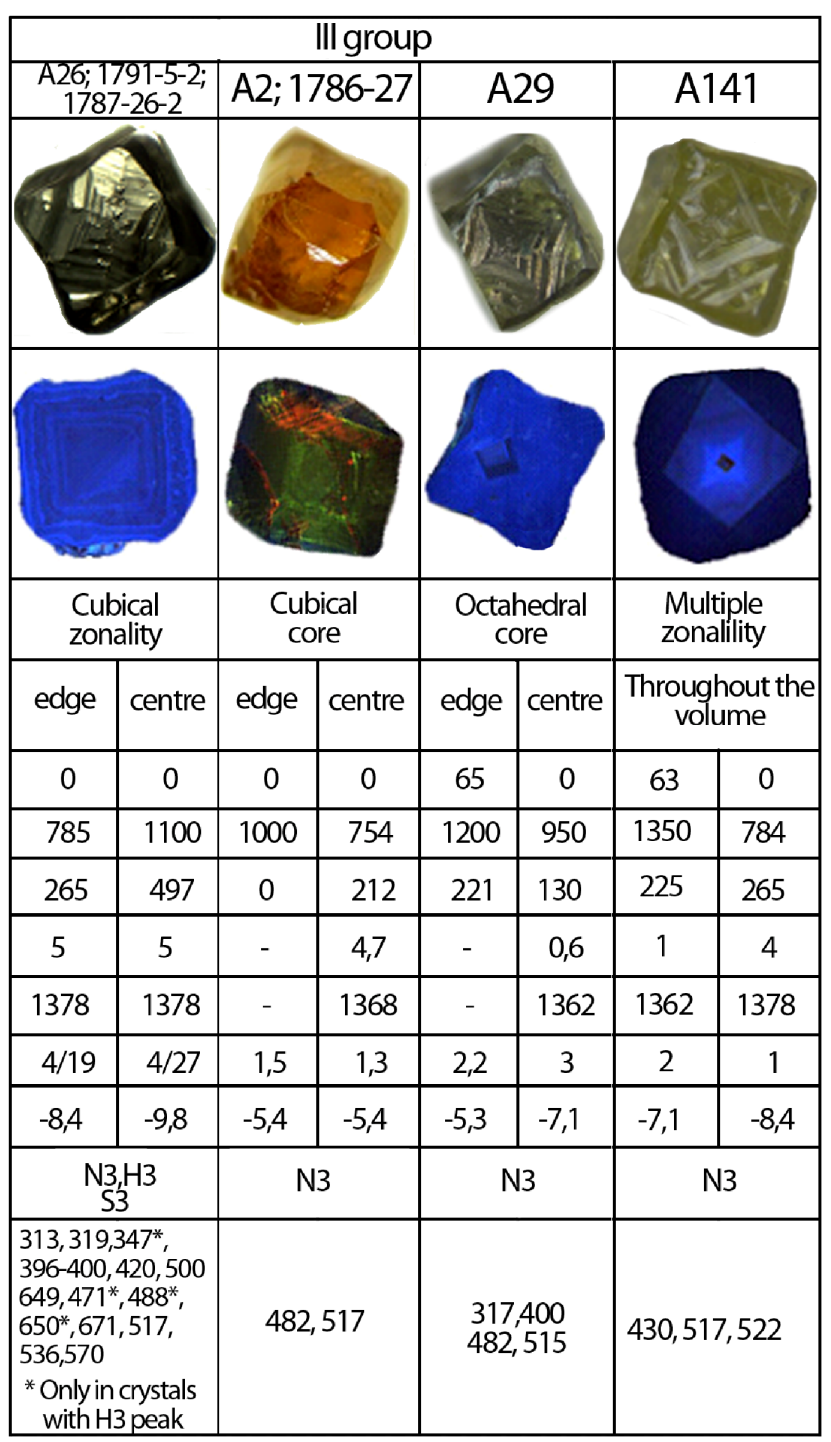

The results of our study confirm that the multiple-zonal and plastically deformed cubes from M.V. Lomonosov deposit is an unique examples of the diamonds from kimberlites, such crystals have not been described among diamonds from industrially diamondiferous kimberlites in Yakutian Province (Siberia, East Russia). 


\section{$10^{\text {th }}$ International Kimberlite Conference, Bangalore - 2012}

\section{References:}

Galimov E.M. (1984) Variations in the isotopic composition of diamonds and their relationship to the conditions of diamond formation.// geochemistry, №8. pp. 1091-1117

Galimov E.M., Zaharchenco O.D., Malcev K.A., Mahin A.I. (1994) Carbon isotope compositions of diamonds from kimberlite pipes of the Arkhangelsk Region/ / geochemistry. №1, pp. 74-76.

Garanin V.K., Kudryvceva G.P., Posuhova T.V., Vershak V.V., Verichev E.M., Garanin K.V. (2001) Two types of diamond-bearing kimberlites in the Arkhangelsk province. Geology and Exploration. №4, pp. 36-49

Makeev A.B., Kriulina G.Y, Lutoev V.P., Ivannikov P.V. (2011) Features cuboids of diamond pipes of the Arkhangelsk. Bulletin of the Institute of Geology of Komi Science Center UrO RSA №3, pp.2-6.

Kudryvceva G.P., Posuhova T.V., Vershak V.V. и др. (2005) Atlas "Morphogenesis of the diamond and mineral-satellites of kimberlites and related rocks of the Arkhangelsk diamond province." Moscow: Polar Circle, 624 c.

Orlov Y.L. (1984) Mineralogy of the diamond. Nauka, $263 \mathrm{c}$.

Boyd S. R., Kiflawi I., Woods G. S (1994) The relationship between infrared absorption and the $\mathrm{A}$ defect concentration in diamond // Phil. Mag. B. V.69, pp.1149-1153.

Boyd. S. R., Kiflawi I., Woods G. S. (1995) Infrared absorption by the B nitrogen aggregate in diamond // Phil. Mag. B. V. 72, pp. 351-361.

Taylor W.R., Milledge H.J. (1995) Nitrogen aggregation character, thermal history and stable isotope composition of some xenolith-derived diamonds from Roberts Victor and Finch // Sixth Internal. Kimberlite Conf. Extended Abstr. Novosibirsk, pp. 620-622. 